\title{
Brain Protection During Ascending Aortic Repair for Stanford Type A Acute Aortic Dissection Surgery
}

\author{
- Nationwide Analysis in Japan -
}

\author{
Yoshiyuki Tokuda, MD, PhD; Hiroaki Miyata, MD, PhD; Noboru Motomura, MD, PhD; \\ Hideki Oshima, MD, PhD; Akihiko Usui, MD, PhD; Shinichi Takamoto, MD, PhD; \\ Japan Adult Cardiovascular Database Organization
}

\begin{abstract}
Background: The optimal brain protection strategy for use during acute type A aortic dissection surgery is controversial.
\end{abstract}

\begin{abstract}
Methods and Results: We reviewed the results for 2 different methods: antegrade cerebral perfusion (ACP) and retrograde cerebral perfusion (RCP), during ascending aortic repair for acute type $A$ aortic dissection for the period between 2008 and 2012 nationwide. Cases involving root repair, arch vessel reconstruction and/or concomitant procedures were excluded. Using the Japan Adult Cardiovascular Surgery Database, a total of 4,128 patients (ACP, $n=2,769$; RCP, $n=1,359$; mean age, $69.1 \pm 11.8$ years; male $41.9 \%$ ) were identified. The overall operative mortality was $8.6 \%$. Following propensity score matching, among 1,320 matched pairs, differences in baseline characteristics between the 2 patient groups diminished. Cardiac arrest time (ACP $116 \pm 36$ vs. RCP $102 \pm 38$ min, $P<0.001$ ), perfusion time (192 \pm 54 vs. $174 \pm 53 \mathrm{~min}, \mathrm{P}<0.001)$ and operative time ( $378 \pm 117$ vs. $340 \pm 108 \mathrm{~min}, \mathrm{P}<0.001)$ were significantly shorter in the RCP group. There were no significant differences between the 2 groups regarding the incidence of operative mortality or neurological complications, including stroke (ACP 11.2\% vs. RCP 9.7\%). Postoperative ventilation time was significantly longer in the ACP group (ACP 128.9 \pm 355.7 vs. RCP 98.5 $\pm 301.7 \mathrm{~h}, \mathrm{P}=0.018$ ). There were no differences in other early postoperative complications, such as re-exploration, renal failure, and mediastinitis.
\end{abstract}

Conclusions: Among patients undergoing dissection repair without arch vessel reconstruction, RCP had similar mortality and neurological outcome to ACP. (Circ J 2014; 78: 2431-2438)

Key Words: Aorta; Cardiopulmonary bypass; Dissection

A cute type A aortic dissection is a life-threatening emergency associated with major morbidity and mortality requiring immediate surgical treatment., ${ }^{1,2}$ With respect to improving surgical outcomes, the optimal selection of a brain protection strategy is of critical importance. In recent decades, various brain protection methods have been used in the field of surgery of the thoracic aorta based on the concept of hypothermic circulatory arrest (HCA). ${ }^{3}$ In addition to the use of HCA alone, various cerebral perfusion strategies have been developed to prolong the safe duration of circulatory arrest. In particular, 2 major methods are generally utilized as adjuncts to HCA: selective antegrade cerebral perfusion (ACP), which maintains the cerebral circulation using cold blood perfusion via the arch vessels with separate cannulas, ${ }^{4}$ and retrograde cerebral perfusion (RCP), an alternative method for brain protection during deep hypothermic circulation arrest achieved using the perfusion of a small volume of blood via the superior vena cava in a retrograde manner. ${ }^{5}$

\section{Editorial p 2378}

In the setting of acute aortic dissection surgery, because there is a possibility of involvement of dissection in the arch vessels, selecting the brain protection strategy is particularly difficult and complex. In such cases, ACP can cause brain ischemia due to worsening of malperfusion despite a sufficient blood supply through the perfusion cannula. ${ }^{6}$ No consensus, therefore, has been reached among cardiac surgeons concerning the optimal strategy for brain protection during acute type A aortic dissection surgery.

Received May 26, 2014; revised manuscript received July 22, 2014; accepted July 23, 2014; released online August 28, 2014 Time for primary review: 34 days

Department of Cardiac Surgery, Nagoya University Graduate School of Medicine, Nagoya (Y.T., H.O., A.U.); Japan Cardiovascular Surgery Database Organization, Tokyo (H.M., N.M., S.T.), Japan

Mailing address: Yoshiyuki Tokuda, MD, PhD, Department of Cardiac Surgery, Nagoya University Graduate School of Medicine, 65 Tsurumai, Showa-ku, Nagoya 466-8550, Japan. E-mail: tokuda@mxb.mesh.ne.jp

ISSN-1346-9843 doi:10.1253/circj.CJ-14-0565

All rights are reserved to the Japanese Circulation Society. For permissions, please e-mail: cj@j-circ.or.jp 
Given that acute type A dissection repair is usually performed on an emergency or urgent basis, conducting a randomized control trial to compare brain protection methods, although desirable, is difficult in practice. For this reason, a comparative clinical study using a large-scale database is a good alternative for assessing the superiority of methods of brain protection, while achieving a higher level of evidence.

The primary purpose of the present study was to compare brain protection methods in order to identify the optimal brain protection strategy for use in acute type A aortic dissection surgery. The broad range of preoperative conditions, anatomic features and surgical procedures observed in this setting has hampered comparisons of postoperative outcomes. We used the Japan Adult Cardiovascular Surgery Database (JACVSD) in order to obtain a sufficient number of cases to enable riskadjusted analysis. The surgical treatment of type A aortic dissection primarily consists of the replacement of the ascending aorta in order to excise the entry tears and prevent an expansion of the area of dissection toward the aortic root with consequent rupture into the pericardial sac. In order to minimize procedure-related bias, the present study focused on the outcome of the most common and simple form of acute type A aortic dissection repair: isolated replacement of the area of the ascending aorta. The present study therefore excluded patients who underwent repair with root or arch vessel reconstruction and/or repair performed in association with other concomitant procedures.

\section{Methods}

\section{JACVSD}

The JACVSD was established in 2000 to assess the surgical outcomes of cardiovascular procedures on a multicenter basis throughout Japan. The JACVSD currently collects clinical information from 520 Japanese hospitals performing cardiovascular surgery, as of April 2013. The form used for data collection includes a total of more than 250 variables (the definitions are available online at http://www.jacvsd.umin.jp) that are almost identical to those used in the Society of Thoracic Surgeons (STS) National Database (the definitions are available online at http://sts.org). The methods used for data collection in the JACVSD are described in a previous publication. ${ }^{7}$ The data collection protocol was approved by the Institutional Review Board of each participating hospital. The use of data for the present study was approved by the Data Utilization Committee of the Japan Cardiovascular Surgery Database Organization. The committee waived the individual consent for the present study. The data collection process achieved a high level of completion, with missing data representing $<2 \%$ of all assembled data. The accuracy of the submitted data was maintained using a data audit achieved via random, monthly visits by administrative office members to participating hospitals in which the data were verified using clinical records.

\section{Subjects}

We examined isolated primary repair operations of Stanford type A acute aortic dissection (performed within 14 days after onset) performed between 1 January 2008 and 31 December 2012 in which the range of repair was confined to the ascending aorta. Cases involving repair with root or arch vessel reconstruction (partial or total) or repair associated with other concomitant major surgical procedures, such as valve surgery or coronary artery bypass grafting, were excluded. So-called hemi arch replacement (replacement of the proximal aorta with resection of some portion of the concavity of the aortic arch, leaving the convexity and origin of the arch vessels intact) was not deemed to constitute replacement of the aortic arch, and such cases were therefore included in the present study.

Cases involving records with missing or out of range data for age, sex or the 30-day status, as well as those in which the brain protection method was not specified, were excluded. With respect to the brain protection method, an initial 2,769 patients were treated with $\mathrm{ACP}, 1,359$ were treated with RCP, 832 were treated with isolated HCA alone and 14 were treated with other methods. Among these patients, those treated with ACP or RCP were selected for the present analysis. After cleaning the data, the subject group included in the analysis consisted of 4,128 cases ( $\mathrm{ACP}, \mathrm{n}=2,769 ; \mathrm{RCP}, \mathrm{n}=1,359)$ of isolated type A acute aortic dissection repair without arch vessel or root reconstruction in Japan.

\section{Endpoints}

The primary outcome measured from the JACVSD was the operative mortality rate. Operative mortality was defined as death occurring within the index hospitalization, regardless of the length of hospital stay, and including any deaths occurring after discharge from the hospital up to 30 days from the date of surgery. A hospital-to-hospital transfer was not considered discharge. ${ }^{8}$ The definitions of postoperative outcomes were determined based on the JACVSD definitions. Using a definition obtained from previous studies, major morbidity was defined as the occurrence of any of 5 postoperative in-hospital complications: stroke; reoperation for bleeding; need for mechanical ventilation $>24$ h postoperatively due to respiratory failure; renal failure associated with newly required dialysis; or mediastinitis. ${ }^{9}$ In addition to evaluating stroke as a new neurological dysfunction, we assessed the incidence of transient neurological dysfunction, continuous coma $>24 \mathrm{~h}$ and paraparesis/paraplegia as neurological complications, as per the JACVSD protocol. ${ }^{10}$ Transient neurological dysfunction was defined as a focal neurologic deficit lasting $<72 \mathrm{~h}$ or postoperative delirium, agitation, confusion and/or a decreased level of consciousness without the detection of any new structural abnormalities on imaging. ${ }^{11}$

\section{Statistical Analysis}

We compared the baseline demographics of the patients who underwent RCP surgery with those who underwent ACP surgery. Differences between the 2 brain protection strategy groups were determined using bivariate tests, including Fisher's exact test and the chi-squared test for categorical covariates and the un-paired t-test or Wilcoxon rank-sum test for continuous covariates. The data are given as mean \pm SD.

For risk-adjusted comparisons, a multivariate logistic regression model was applied to determine the effects of RCP. Using stepwise regression with backward elimination, the baseline characteristics were listed as independent variables, while mortality and major morbidities were established as the dependent variable for the multivariate logistic regression analysis.

The second method of adjustment involved matching patients with a similar probability of receiving RCP. Because the patients were not randomly assigned to receive RCP, we used propensity score matching to adjust for differences in the preoperative factors. ${ }^{12}$ We performed a 1-to-1 matched analysis without replacement based on the estimated propensity score, calculated from variables for each patient collected from the baseline characteristics listed in Table 1. The log odds of the probability that a patient received RCP (the "logit") was modeled as a function of the confounders identified and included in the dataset. Using the estimated logits, we first randomly 


\begin{tabular}{|c|c|c|c|}
\hline Characteristics & $\begin{array}{c}\text { ACP } \\
(n=2,769)\end{array}$ & $\begin{array}{c}\text { RCP } \\
(n=1,359)\end{array}$ & P-value \\
\hline Age (years) & & & 0.034 \\
\hline$\leq 60$ & $559(20.2)$ & $327(24.1)$ & \\
\hline $61-65$ & $360(13.0)$ & $189(13.9)$ & \\
\hline $66-70$ & $403(14.6)$ & $191(14.1)$ & \\
\hline $71-75$ & $446(16.1)$ & $216(15.9)$ & \\
\hline $75-80$ & $523(18.9)$ & $238(17.5)$ & \\
\hline$\geq 81$ & $478(17.3)$ & $198(14.6)$ & \\
\hline Mean age (years) & $69.6 \pm 11.6$ & $68.2 \pm 12.1$ & 0.001 \\
\hline Male gender & $1,146(41.4)$ & $583(42.9)$ & 0.365 \\
\hline Smoking history & $962(34.7)$ & $510(37.5)$ & 0.084 \\
\hline CLD (moderate-severe) & $49(1.8)$ & $21(1.5)$ & 0.701 \\
\hline Diabetes & $160(5.8)$ & $100(7.4)$ & 0.056 \\
\hline Diabetes requiring medication & $91(3.3)$ & $50(3.7)$ & 0.524 \\
\hline Hypertension & $2,166(78.2)$ & $1,064(78.3)$ & 0.968 \\
\hline Renal dysfunction & $172(6.2)$ & $74(5.4)$ & 0.363 \\
\hline Hepatic dysfunction & $139(5.0)$ & $52(3.8)$ & 0.098 \\
\hline History of CBV event & $375(13.5)$ & $185(13.6)$ & 0.961 \\
\hline Recent CBV event (within the past 2 weeks) & $216(7.8)$ & $102(7.5)$ & 0.757 \\
\hline Carotid stenosis & $86(3.1)$ & $26(1.9)$ & 0.032 \\
\hline Peripheral vascular disease & $354(12.8)$ & $115(8.5)$ & $<0.001$ \\
\hline$\geq 2$-vessel CAD & $11(0.4)$ & $6(0.4)$ & 0.801 \\
\hline \multicolumn{4}{|l|}{ Cardiac symptom } \\
\hline NYHA III or IV & $794(28.7)$ & $302(22.2)$ & $<0.001$ \\
\hline NYHA IV & $599(21.6)$ & $227(16.7)$ & $<0.001$ \\
\hline CHF (within the past 2 weeks) & $127(4.6)$ & $85(6.3)$ & 0.024 \\
\hline Cardiogenic shock & $538(19.4)$ & $262(19.3)$ & 0.933 \\
\hline Angina symptom (CCS class $\geq 2$ ) & $207(7.5)$ & $63(4.6)$ & $<0.001$ \\
\hline \multicolumn{4}{|l|}{ LV function } \\
\hline Good ( $E F \geq 60 \%)$ & 1,999 (72.2) & $910(67.0)$ & 0.001 \\
\hline Medium (EF 30-60\%) & $698(25.2)$ & $401(29.5)$ & 0.003 \\
\hline Low $(E F<30 \%)$ & $52(1.9)$ & $20(1.5)$ & 0.378 \\
\hline \multicolumn{4}{|l|}{ Heart valve disorder } \\
\hline Aortic insufficiency ( $\geq 11 / I V)$ & $641(23.1)$ & $253(18.6)$ & 0.001 \\
\hline Mitral insufficiency ( $\geq \mathrm{II} / \mathrm{IV}$ ) & 107 (3.9) & $47(3.5)$ & 0.542 \\
\hline Tricuspid insufficiency ( $\geq \mathrm{II} / \mathrm{IV}$ ) & $126(4.6)$ & $56(4.1)$ & 0.573 \\
\hline Arrhythmia & $199(7.2)$ & $79(5.8)$ & 0.099 \\
\hline Atrial fibrillation & $142(5.1)$ & $48(3.5)$ & 0.022 \\
\hline Obesity (BMI $\geq 30$ ) & $139(5.0)$ & $91(6.7)$ & 0.030 \\
\hline Previous cardiac surgery & $15(0.5)$ & $2(0.1)$ & 0.072 \\
\hline \multicolumn{4}{|l|}{ Priority of surgery } \\
\hline Urgent & $307(11.1)$ & $187(13.8)$ & 0.014 \\
\hline Emergency & 2,338 (84.4) & $1,120(82.4)$ & 0.106 \\
\hline
\end{tabular}

Data given as $\mathrm{n}(\%)$ or mean \pm standard deviation (SD). Moderate chronic lung disease defined as FEV1 $50-59 \%$ of the predicted value and/or the use of chronic steroid therapy to treat lung disease. Severe chronic lung disease defined as FEV1 $<50 \%$ predicted and/or a room air $\mathrm{PaO}_{2}<60 \mathrm{mmHg}$ or room air $\mathrm{PaCO}_{2}>50 \mathrm{mmHg}$.

$\mathrm{ACP}$, antegrade cerebral perfusion; BMI, body mass index; CAD, coronary artery disease; CBV, cerebrovascular; CCS, Canadian Cardiovascular Society; CHF, congestive heart failure; CLD, chronic lung disease; EF, ejection fraction; LV, left ventricular; NYHA, New York Heart Association; RCP, retrograde cerebral perfusion.

selected a patient in the RCP group and then matched that patient with a patient in the ACP group with the closest estimated logit value. Patients in the RCP group with an estimated logit within $0.6 \mathrm{SD}$ of the selected patients in the ACP group were eligible for matching. We selected 0.6 SD because this has been shown to eliminate approximately $90 \%$ of the bias present in observed confounders ${ }^{13}$ (C-statistic of the propensity model, 0.614). The differences in clinical variables were tested on univariate analysis.

\section{Results}

\section{Baseline Characteristics and Clinical Outcome}

Among the subject group, 2,769 patients underwent ACP and 1,359 patients underwent RCP. The characteristics of the 2 groups are listed in Table 1 . Overall, the mean patient age was 


\begin{tabular}{|c|c|c|c|c|}
\hline & $\begin{array}{c}\text { ACP } \\
(n=2,769)\end{array}$ & $\begin{array}{c}\mathrm{RCP} \\
(n=1,359)\end{array}$ & $\begin{array}{l}\text { Overall } \\
(n=4,128)\end{array}$ & P-value \\
\hline \multicolumn{5}{|l|}{ Intraoperative variables } \\
\hline Operative time (min) & $379.0 \pm 115.8$ & $341.2 \pm 108.8$ & $366.5 \pm 114.9$ & $<0.001$ \\
\hline Perfusion time (min) & $192.3 \pm 53.5$ & $174.3 \pm 53.0$ & $186.4 \pm 54.0$ & $<0.001$ \\
\hline Cardiac arrest time (min) & $115.9 \pm 37.6$ & $102.1 \pm 38.3$ & $111.4 \pm 38.4$ & $<0.001$ \\
\hline Minimal core temperature $\left({ }^{\circ} \mathrm{C}\right)$ & $24.5 \pm 2.9$ & $22.6 \pm 3.0$ & $23.9 \pm 3.1$ & $<0.001$ \\
\hline Operative mortality & $246(8.9)$ & $109(8.1)$ & $355(8.6)$ & 0.41 \\
\hline $\begin{array}{l}\text { Composite operative mortality and major } \\
\text { complication }\end{array}$ & $1,092(39.4)$ & $482(35.5)$ & $1,574(38.1)$ & 0.01 \\
\hline Reoperation for bleeding & $137(4.9)$ & $75(5.5)$ & $212(5.1)$ & 0.45 \\
\hline Renal failure & $314(11.3)$ & $144(10.6)$ & $458(11.1)$ & 0.49 \\
\hline De novo hemodialysis & $175(6.3)$ & $69(5.1)$ & $244(5.9)$ & 0.12 \\
\hline \multicolumn{5}{|l|}{ Cardiac complications } \\
\hline Cardiac arrest & $50(1.8)$ & $27(2.0)$ & $77(1.9)$ & 0.71 \\
\hline Cardiac tamponade & $122(4.4)$ & $50(3.7)$ & $172(4.2)$ & 0.28 \\
\hline Heart block requiring pacemaker & $15(0.5)$ & $8(0.6)$ & $23(0.6)$ & 0.83 \\
\hline Atrial fibrillation & $589(21.3)$ & $298(21.9)$ & $887(21.5)$ & 0.63 \\
\hline Perioperative MI & $30(1.1)$ & $8(0.6)$ & $38(0.9)$ & 0.16 \\
\hline \multicolumn{5}{|l|}{ Infection } \\
\hline Mediastinitis & $53(1.9)$ & $24(1.8)$ & $77(1.9)$ & 0.81 \\
\hline Septicemia & $90(3.3)$ & $33(2.4)$ & $123(3.0)$ & 0.17 \\
\hline Pneumonia & $185(6.7)$ & $95(7.0)$ & $280(6.8)$ & 0.74 \\
\hline Prolonged ventilation & $834(30.1)$ & $339(24.9)$ & $1,173(28.4)$ & $<0.001$ \\
\hline Neurological complications, any & $514(18.6)$ & $248(18.2)$ & $762(18.5)$ & 0.83 \\
\hline Stroke & $311(11.2)$ & $132(9.7)$ & $443(10.7)$ & 0.15 \\
\hline Transient neurological dysfunction & $121(4.4)$ & $61(4.5)$ & $182(4.4)$ & 0.87 \\
\hline Coma & $149(5.4)$ & $74(5.4)$ & $223(5.4)$ & 0.94 \\
\hline Paraparesis/Paraplegia & 109 (3.9) & $62(4.6)$ & $171(4.1)$ & 0.36 \\
\hline GI tract complication & $99(3.6)$ & $37(2.7)$ & $136(3.3)$ & 0.16 \\
\hline Multiple organ failure & $86(3.1)$ & $43(3.2)$ & $129(3.1)$ & 0.92 \\
\hline Transfusion & $2,730(98.6)$ & $1,332(98.0)$ & $4,062(98.4)$ & 0.19 \\
\hline Length of stay ICU $>8$ days & 809 (29.2) & $364(26.8)$ & $1,173(28.4)$ & 0.11 \\
\hline Postoperative ventilation time (h) & $134.8 \pm 360.0$ & $100.3 \pm 304.0$ & $123.5 \pm 343.0$ & 0.001 \\
\hline Re-admission & $38(1.4)$ & $19(1.4)$ & $57(1.4)$ & 1.00 \\
\hline
\end{tabular}

Data given as $\mathrm{n}(\%)$ or mean $\pm \mathrm{SD}$. Gl, gastrointestinal; ICU, intensive care unit; MI, myocardial infarction. Other abbreviations as in Table 1.

$69.1 \pm 11.8$ years, and $41.9 \%$ of the patients were male. Emergency procedures were required in $83.8 \%$ of cases (defined as a procedure that began immediately after surgical intervention was selected), while $12.0 \%$ of the patients required urgent procedures (defined as a procedure that began within $24 \mathrm{~h}$ of the decision to perform surgery).

The overall operative mortality was $8.6 \%$. The specific morbidity rates in both groups are given in Table 2 . There were no differences in operative mortality between the ACP $(8.9 \%)$ and RCP $(8.1 \%)$ groups. Moreover, there were no significant differences in the stroke rate between the 2 groups: $11.2 \%$ in the ACP group and $9.7 \%$ in the RCP group. The postoperative ventilation time was significantly longer in the ACP group (ACP $134.8 \pm 360.0$ vs. RCP 100.3 $\pm 304.0 \mathrm{~h}, \mathrm{P}=0.001$ ). The need for prolonged ventilation ( $>24 \mathrm{~h}$ due to respiratory reasons) was therefore more frequent in the ACP group (ACP 30.1\% vs. RCP $24.9 \%, \mathrm{P}<0.001)$. Given that prolonged ventilation was categorized as a major complication, the composite mortality and major complication rate was higher in the ACP group (ACP $39.4 \%$ vs. RCP $35.5 \%, \mathrm{P}=0.01$ ). Otherwise, there were no differences in the rates of early postoperative complications.

\section{Risk-Adjusted Analysis}

As to the risk-adjusted analysis, the effects of RCP were assessed using logistic regression analysis, the results of which are given in Table 3. Among the 5 major postoperative morbidities (stroke; reoperation due to bleeding; prolonged ventilation; de novo dialysis; or mediastinitis), operative mortality and neurological complications, only the need for prolonged ventilation was significantly different, with a higher rate in the ACP group.

The odds ratio of RCP over ACP for prolonged ventilation was 0.77 (95\% confidence interval: $0.66-0.90, \mathrm{P}=0.001$; the odds ratio of ACP over RCP was 1.30).

\section{Propensity-Matched Pairs Analysis}

Based on the results given in the previous section, we evaluated 1,320 ACP patients and 1,320 RCP patients based on case matching using the propensity score. As a result, the differences in the preoperative factors decreased substantially. There were no significant differences in the various preoperative factors between the 2 post-matching groups (Table 4).

Similar to that observed for the overall cohort data, the 


\begin{tabular}{|c|c|c|}
\hline Outcome & OR (RCP over ACP) $(95 \%$ Cl) & P-value \\
\hline Operative mortality & $0.91(0.71-1.17)$ & \\
\hline Reoperation for bleeding & $1.18(0.88-1.58)$ & 0.28 \\
\hline De novo hemodialysis & $0.81(0.60-1.10)$ & 0.17 \\
\hline Prolonged ventilation & $0.77(0.66-0.90)$ & 0.001 \\
\hline Mediastinitis & $0.92(0.57-1.52)$ & 0.76 \\
\hline Neurological complications, any & $1.02(0.86-1.22)$ & 0.81 \\
\hline Stroke & $0.87(0.70-1.08)$ & 0.21 \\
\hline Transient neurological dysfunction & $1.03(0.75-1.42)$ & 0.85 \\
\hline Coma & $1.1(0.81-1.50)$ & 0.53 \\
\hline Paraparesis/Paraplegia & $1.17(0.84-1.61)$ & 0.35 \\
\hline
\end{tabular}

$\mathrm{Cl}$, confidence interval; OR, odds ratio. Other abbreviations as in Table 1.

operative time (ACP $378 \pm 117$ vs. RCP $340 \pm 108 \mathrm{~min}, \mathrm{P}<0.001$ ), perfusion time (ACP $192 \pm 54$ vs. $174 \pm 53 \mathrm{~min}, \mathrm{P}<0.001$ ) and cardiac arrest time (ACP $116 \pm 36$ vs. RCP $102 \pm 38$ min, $\mathrm{P}<0.001$ ) were significantly longer and the minimal core temperature was higher (ACP $24.5 \pm 2.9$ vs. $\mathrm{RCP} 22.6 \pm 3.0^{\circ} \mathrm{C}$ ) in the $\mathrm{ACP}$ group. The postoperative outcomes of the propensity matched pairs are given in Table 5 . There were no significant differences between the 2 groups regarding operative mortality (ACP $8.8 \%$ vs. RCP $7.7 \%$ ) or the various neurological complications. Specifically, there were no significant differences in the rate of stroke (ACP 11.2\% vs. RCP 9.7\%), coma (ACP $4.9 \%$ vs. RCP 5.4\%), paraparesis/paraplegia (ACP $4.2 \%$ vs. RCP $4.5 \%$ ), transient neurological dysfunction (ACP $4.9 \%$ vs. RCP $4.5 \%$ ) or any other neurological complications (ACP $18.7 \%$ vs. RCP 18.1\%). A higher rate of prolonged ventilation was again observed in the ACP group (ACP 29.9\% vs. RCP $24.7 \%$, $\mathrm{P}=0.003$ ), and the postoperative ventilation time was also significantly longer in the ACP group (ACP $128.9 \pm 355.7$ vs. RCP $98.5 \pm 301.7 \mathrm{~h}, \mathrm{P}=0.018)$. Otherwise, there were no differences in the rate of early postoperative complications, including other major complications, such as re-exploration, renal failure and mediastinitis.

\section{Discussion}

The present study found that if arch vessel reconstruction is not involved in the dissection repair procedure, RCP provides similar clinical outcomes regarding both mortality and neurological complication rates in comparison to ACP. Moreover, the cardiac arrest time, perfusion time and operative time were all significantly shorter in the RCP group whereas the minimal core temperature was lower in the RCP group. In addition, the need for prolonged ventilation $(>24 \mathrm{~h}$ ) occurred more frequently in the ACP group. An analysis of the overall cohort, as well as a risk-adjusted analysis and propensity matching analysis, confirmed these results.

Currently, there is no consensus regarding the optimal strategy for providing brain protection during acute type A aortic dissection surgery. There have been several reports comparing the effectiveness of ACP and RCP in cases involving atheromatous thoracic aortic aneurysms. ${ }^{10,14-17}$ These studies found either no obvious differences between the methods, or a slight superiority of ACP. The superiority of ACP with respect to neurological outcomes is especially clear among patients undergoing arch replacement with separate arch vessel reconstruction using branched grafts. The rate of transient neurological dysfunction is generally lower if ACP is applied in such cases. ${ }^{15,16}$ In the present study, the rate of transient neurological dysfunction was similar between the ACP group and the RCP group, but it should be noted that inter-observer differences in evaluating the transient neurological dysfunction may have been present, because the criteria for delirium or agitation are not clear in the JACVSD system.

The situation is more complex, however, in the setting of dissection repair, in that brain protection must be provided in the presence of possible branch dissection and malperfusion of the cerebral vessels. There have also been a few previous studies comparing the efficacy of different brain protection methods in dissection repair, specifically. For example, Wiedemann et al reported that patients who receive ACP have somewhat better neurological and survival outcomes, although the difference was not significant on multivariate analysis. ${ }^{18}$ Importantly, their subjects included patients who underwent arch vessel reconstruction. The background of their study was therefore more favorable for ACP use and differs from the present setting. A similar study by Comas et al found that the use of ACP in the setting of dissection repair results in similar neurological outcome compared to that obtained with other techniques. The authors emphasized that performing aortic clamping prior to circulatory arrest carries a risk of stroke. ${ }^{19}$ Both the brain protection method and perfusion strategy (antegrade or retrograde perfusion) or cannulation site strategy can affect outcome. In particular, antegrade perfusion through the true lumen (via axillary cannulation or central aortic cannulation) has been reported to be associated with better survival. ${ }^{20}$

In general, both ACP and RCP have advantages and disadvantages with regard to brain protection. ACP could be used to provide a reliable cerebral circulation, but it requires the placement of additional cannulas on the arch branches, which potentially increases the chance of embolism or worsening of malperfusion. ${ }^{6}$ Furthermore, the use of additional pump circuits and cannulas clutters the operative field. In the presence of such cannulas, performing anastomosis becomes more complex, which may possibly elongate the time required to complete anastomosis. In the present study, cardiac arrest time, which was approximately equivalent to the sum of the time required for distal and proximal anastomosis, was significantly elongated in the ACP group. Previous studies have similarly noted a tendency toward a longer distal circulatory arrest time (lower body visceral ischemic time) in patients treated with ACP compared to those treated with RCP. ${ }^{14}$ The shorter anastomosis time in the RCP group may have been mainly related to the simpler anastomosis performed, but it could also have been surgeon related, because RCP used to be an established 


\begin{tabular}{|c|c|c|c|}
\hline Characteristics & $\begin{array}{c}\text { ACP } \\
(n=1,320)\end{array}$ & $\begin{array}{c}\text { RCP } \\
(n=1,320)\end{array}$ & P-value \\
\hline Age (years) & & & 0.998 \\
\hline$\leq 60$ & $305(23.1)$ & $301(22.8)$ & \\
\hline $61-65$ & $182(13.8)$ & $185(14.0)$ & \\
\hline $66-70$ & $193(14.6)$ & $187(14.2)$ & \\
\hline $71-75$ & $206(15.6)$ & $214(16.2)$ & \\
\hline $75-80$ & $238(18.0)$ & $237(18.0)$ & \\
\hline$\geq 81$ & $196(14.8)$ & $196(14.8)$ & \\
\hline Mean age (years) & $68.5 \pm 12.0$ & $68.6 \pm 11.9$ & 0.880 \\
\hline Male gender & $577(43.7)$ & $559(42.3)$ & 0.504 \\
\hline Smoking history & $491(37.2)$ & $491(37.2)$ & 1.000 \\
\hline CLD (moderate-severe) & $21(1.6)$ & $19(1.4)$ & 0.874 \\
\hline Diabetes & $84(6.4)$ & $90(6.8)$ & 0.695 \\
\hline Diabetes requiring medication & $54(4.1)$ & $47(3.6)$ & 0.543 \\
\hline Hypertension & $1,039(78.7)$ & $1,031(78.1)$ & 0.741 \\
\hline Renal dysfunction & $94(7.1)$ & $72(5.5)$ & 0.092 \\
\hline Hepatic dysfunction & $61(4.6)$ & $52(3.9)$ & 0.442 \\
\hline History of CBV event & $164(12.4)$ & $181(13.7)$ & 0.356 \\
\hline Recent CBV event (within the past 2 weeks) & $105(8.0)$ & $101(7.7)$ & 0.828 \\
\hline Carotid stenosis & $36(2.7)$ & $26(2.0)$ & 0.247 \\
\hline Peripheral vascular disease & $97(7.3)$ & $114(8.6)$ & 0.251 \\
\hline \multicolumn{4}{|l|}{ Extent of CAD } \\
\hline$\geq 2$ vessel $C A D$ & $8(0.6)$ & $7(0.5)$ & 1.000 \\
\hline \multicolumn{4}{|l|}{ Cardiac symptom } \\
\hline NYHA III or IV & $305(23.1)$ & $294(22.3)$ & 0.642 \\
\hline NYHA IV & $225(17.0)$ & $219(16.6)$ & 0.795 \\
\hline CHF (within the past 2weeks) & $75(5.7)$ & $73(5.5)$ & 0.933 \\
\hline Cardiogenic shock & $242(18.3)$ & $249(18.9)$ & 0.605 \\
\hline Angina symptom (CCS class $\geq 2$ ) & $66(5.0)$ & $63(4.8)$ & 0.857 \\
\hline \multicolumn{4}{|l|}{ LV function } \\
\hline Good (EF $\geq 60 \%)$ & $911(69.0)$ & $897(68.0)$ & 0.586 \\
\hline Medium (EF 30-60\%) & $372(28.2)$ & $379(28.7)$ & 0.796 \\
\hline Low $(E F<30 \%)$ & $27(2.0)$ & $17(1.3)$ & 0.171 \\
\hline \multicolumn{4}{|l|}{ Heart valve disorder } \\
\hline Aortic insufficiency ( $\geq 1 \mathrm{I} / \mathrm{IV}$ ) & $235(17.8)$ & $251(19.0)$ & 0.451 \\
\hline Mitral insufficiency ( $\geq 1 \mathrm{I} / \mathrm{IV}$ ) & $31(2.3)$ & $47(3.6)$ & 0.084 \\
\hline Tricuspid insufficiency ( $\geq \mathrm{II} / \mathrm{IV}$ ) & $48(3.6)$ & $56(4.2)$ & 0.484 \\
\hline Arrhythmia & $64(4.8)$ & $78(5.9)$ & 0.262 \\
\hline Atrial fibrillation & $36(2.7)$ & $48(3.6)$ & 0.222 \\
\hline Obesity (BMI $\geq 30$ ) & $81(6.1)$ & $75(5.7)$ & 0.680 \\
\hline Previous cardiac surgery & $3(0.2)$ & $2(0.2)$ & 1.000 \\
\hline \multicolumn{4}{|l|}{ Priority of surgery } \\
\hline Urgent & $146(11.1)$ & $179(13.6)$ & 0.058 \\
\hline Emergency & $1,111(84.2)$ & $1,093(82.8)$ & 0.373 \\
\hline
\end{tabular}

Data given as $\mathrm{n}(\%)$ or mean \pm SD. Abbreviations as in Table 1 .

procedure only at major aortic centers and by well-experienced surgeons.

In contrast, RCP has the drawback of a limited safe duration. In general, the RCP procedure should not exceed $60 \mathrm{~min}$, and a longer RCP duration has been reported to be associated with the incidence of stroke. ${ }^{21}$ In the present study, however, the anastomosis time normally did not exceed the safe duration of RCP, given that cases involving branch vessel reconstruction were excluded. As another drawback, there is a theoretical controversy regarding the blood supply effects of RCP. ${ }^{22}$ If arch vessel dissection is present, however, RCP is a reliable method of providing brain protection because the antegrade perfusion of blood through such vessels potentially results in serious malperfusion and ischemia.

In addition to the data regarding neurological outcome, another finding of the present study is that ACP was found to carry a risk of prolonged ventilation. The pathophysiology of cardiopulmonary bypass (CPB)-induced lung injury is primarily associated with the activation of a systemic inflammatory response via contact of blood with the artificial material of the CPB circuit. ${ }^{23-25}$ In addition, a decreased bronchial artery flow during $\mathrm{CPB}$ has been thought to induce ischemic damage to 


\begin{tabular}{|c|c|c|c|}
\hline & $\begin{array}{c}\text { ACP } \\
(n=1,320)\end{array}$ & $\begin{array}{c}\mathrm{RCP} \\
(\mathrm{n}=1,320)\end{array}$ & P-value \\
\hline \multicolumn{4}{|l|}{ Intraoperative variables } \\
\hline Operative time (min) & $378 \pm 117$ & $340 \pm 108$ & $<0.001$ \\
\hline Perfusion time (min) & $192 \pm 54$ & $174 \pm 53$ & $<0.001$ \\
\hline Cardiac arrest time (min) & $116 \pm 36$ & $102 \pm 38$ & $<0.001$ \\
\hline Minimal core temperature $\left({ }^{\circ} \mathrm{C}\right)$ & $24.5 \pm 2.9$ & $22.6 \pm 3.0$ & $<0.001$ \\
\hline Operative mortality & $116(8.8)$ & $101(7.7)$ & 0.321 \\
\hline $\begin{array}{l}\text { Composite operative mortality and major } \\
\text { complication }\end{array}$ & $509(38.6)$ & $464(35.2)$ & 0.076 \\
\hline Reoperation for bleeding & $58(4.4)$ & $72(5.5)$ & 0.242 \\
\hline Renal failure & $150(11.4)$ & $135(10.2)$ & 0.380 \\
\hline De novo hemodialysis & $80(6.1)$ & $63(4.8)$ & 0.169 \\
\hline \multicolumn{4}{|l|}{ Cardiac complications } \\
\hline Cardiac arrest & $29(2.2)$ & $26(2.0)$ & 0.786 \\
\hline Cardiac tamponade & $63(4.8)$ & $49(3.7)$ & 0.209 \\
\hline Heart block requiring pacemaker & $8(0.6)$ & $8(0.6)$ & 1.000 \\
\hline Atrial fibrillation & $270(20.5)$ & $289(21.9)$ & 0.391 \\
\hline Perioperative MI & $9(0.7)$ & $8(0.6)$ & 1.000 \\
\hline \multicolumn{4}{|l|}{ Infection } \\
\hline Mediastinitis & $24(1.8)$ & $23(1.7)$ & 1.000 \\
\hline Septicemia & $49(3.7)$ & $29(2.2)$ & 0.028 \\
\hline Pneumonia & $80(6.1)$ & $93(7.0)$ & 0.345 \\
\hline Prolonged ventilation $>24 \mathrm{~h}$ & $395(29.9)$ & $326(24.7)$ & 0.003 \\
\hline Neurological complications, any & $247(18.7)$ & $239(18.1)$ & 0.725 \\
\hline Stroke & $148(11.2)$ & $128(9.7)$ & 0.227 \\
\hline Transient neurological dysfunction & $65(4.9)$ & $59(4.5)$ & 0.646 \\
\hline Coma & $65(4.9)$ & $71(5.4)$ & 0.660 \\
\hline Paraparesis/Paraplegia & $56(4.2)$ & $60(4.5)$ & 0.776 \\
\hline Gl tract complication & $41(3.1)$ & $34(2.6)$ & 0.482 \\
\hline Multiple organ failure & $38(2.9)$ & $39(3.0)$ & 1.000 \\
\hline Transfusion & $1,301(98.6)$ & $1,294(98.0)$ & 0.367 \\
\hline Length of stay ICU $>8$ days & $370(28.0)$ & $350(26.5)$ & 0.406 \\
\hline Postoperative ventilation time $(h)$ & $128.9 \pm 355.7$ & $98.5 \pm 301.7$ & 0.018 \\
\hline Re-admission & $12(0.9)$ & $19(1.4)$ & 0.278 \\
\hline
\end{tabular}

Data given as $\mathrm{n}(\%)$ or mean $\pm \mathrm{SD}$. Abbreviations as in Tables 1,2 .

the lungs, ${ }^{26}$ which should be particularly severe during the distal circulatory arrest period of aortic surgery. ${ }^{27}$ Furthermore, in recent years, with the use of ACP, deep hypothermia is not deemed necessary for brain protection, and higher temperatures are often used to shorten the CPB time and maintain coagulation. ${ }^{28}$ End organs that receive no perfusion during the distal circulatory arrest period potentially suffer from "warm" ischemia injury. ${ }^{29-31}$ We speculate that the combination of a longer procedure time and higher temperature observed in the ACP group could result in poor lung protection, thus possibly leading to postoperative respiratory dysfunction.

In the present study, among the patients undergoing dissection repair without arch vessel reconstruction, RCP had similar mortality and neurological outcome to ACP despite insufficient blood supply. Moreover, RCP was found to be associated with a shorter procedure time and a smaller chance of prolonged ventilation. Nevertheless, the selection of the brain protection method should be tailored to the individual patient, taking into consideration several factors, including the possibility of malperfusion, expected distal circulatory arrest time, and preoperative respiratory function. The decision can be modified later if needed, even during the operation. For example, in cases in which a longer distal procedure time is subsequently required, RCP can always be switched to ACP.

\section{Study Limitations}

The present study has certain limitations owing to the nature of the JACVSD. First, no long-term follow-up data for survival were obtained, and all outcomes were restricted to inhospital outcomes. Second, regarding the present subjects, in order to avoid procedure-related bias, we excluded patients undergoing repair with root or arch vessel reconstruction. Therefore, the present findings are not applicable to all dissection repair patients, but rather confined to those undergoing replacement of areas of the ascending aorta. Moreover, because some centers routinely perform arch replacement for acute dissection repair, the present data may not reflect the situation throughout Japan.

Third, the JACVSD lacks several important types of information related to this topic. For example, there is no available information regarding the rate of malperfusion of the cerebral vessels, the cannulation site or the systemic perfusion strategy (antegrade or retrograde) and the duration of brain protection or distal circulatory arrest. In particular, the lack of informa- 
tion on the duration of brain circulatory arrest or the selective cerebral perfusion time is a major weak point. Fourth, the possibility of a selection bias was not completely excluded. There might have been some differences in the selection of the brain protection method according to the case-volume of the centers and the experience of the surgeons. These points were not analyzed.

Despite these limitations, the present study is thus far the most extensive nationwide analysis of the outcome of aortic dissection repair in the modern surgical era in Japan. We thus believe that the present study provides important insight into managing this challenging clinical situation.

\section{Conclusions}

Aortic dissection repair remains a procedure associated with relatively high morbidity and mortality. In the present study, ACP and RCP had similar mortality rates and neurological outcome among the patients undergoing dissection repair without arch vessel reconstruction. Given that ACP and RCP have their own advantages and drawbacks, surgeons should therefore select the most appropriate brain protection method depending on the individual needs of each patient.

\section{Disclosures}

The authors have no conflict of interest to disclose.

\section{References}

1. Ehrlich MP, Ergin MA, McCullough JN, Lansman SL, Galla JD, Bodian CA, et al. Results of immediate surgical treatment of all acute type A dissections. Circulation 2000; 102(19 Suppl 3): III248III 252 .

2. JCS Joint Working Group. Guidelines for diagnosis and treatment of aortic aneurysm and aortic dissection (JCS 2011): Digest version. Circ J 2013; 77: 789-828

3. Griepp RB, Stinson EB, Hollingsworth JF, Buehler D. Prosthetic replacement of the aortic arch. J Thorac Cardiovasc Surg 1975; 70: $1051-1063$.

4. Bachet J, Guilmet D, Goudot B, Dreyfus GD, Delentdecker P, Brodaty $\mathrm{D}$, et al. Antegrade cerebral perfusion with cold blood: A 13-year experience. Ann Thorac Surg 1999; 67: 1874-1878.

5. Ueda Y, Miki S, Kusuhara K, Okita Y, Tahata T, Yamanaka K. Surgical treatment of aneurysm or dissection involving the ascending aorta and aortic arch, utilizing circulatory arrest and retrograde cerebral perfusion. J Cardiovasc Surg (Torino) 1990; 31: 553-558.

6. Ueda T, Shimizu H, Ito T, Kashima I, Hashizume K, Iino Y, et al. Cerebral complications associated with selective perfusion of the arch vessels. Ann Thorac Surg 2000; 70: 1472-1477.

7. Motomura N, Miyata H, Tsukihara H, Okada M, Takamoto S; Japan Cardiovascular Surgery Database Organization. First report on 30day and operative mortality in risk model of isolated coronary artery bypass grafting in Japan. Ann Thorac Surg 2008; 86: 1866-1872.

8. Edmunds LH Jr, Clark RE, Cohn LH, Grunkemeier GL, Miller DC, Weisel RD. Guidelines for reporting morbidity and mortality after cardiac valvular operations: Ad Hoc Liaison Committee for Standardizing Definitions of Prosthetic Heart Valve Morbidity of the American Association for Thoracic Surgery and the Society of Thoracic Surgeons. J Thorac Cardiovasc Surg 1996; 112: 708-711.

9. Tokuda Y, Miyata H, Motomura N, Araki Y, Oshima H, Usui A, et al. Outcome of pericardiectomy for constrictive pericarditis in Japan: A nationwide outcome study. Ann Thorac Surg 2013; 96: 571-576.

10. Usui A, Miyata H, Ueda Y, Motomura N, Takamoto S. Risk-adjusted and case-matched comparative study between antegrade and retrograde cerebral perfusion during aortic arch surgery: Based on the Japan Adult Cardiovascular Surgery Database: The Japan Cardiovascular Surgery Database Organization. Gen Thorac Cardiovasc Surg 2012; 60: 132-139.
11. Misfeld M, Leontyev S, Borger MA, Gindensperger O, Lehmann S, Legare JF, et al. What is the best strategy for brain protection in patients undergoing aortic arch surgery? A single center experience of 636 patients. Ann Thorac Surg 2012; 93: 1502-1508.

12. D'Agostino RB Jr. Propensity score methods for bias reduction in the comparison of a treatment to a non-randomized control group. Stat Med 1998; 17: 2265-2281.

13. Gu XS, Rosenbaum PR. Comparison of multivariate matching methods: Structures, distances, and algorithms. J Comput Graph Stat 1993; 2: 405-420.

14. Milewski RK, Pacini D, Moser GW, Moeller P, Cowie D, Szeto WY, et al. Retrograde and antegrade cerebral perfusion: Results in short elective arch reconstructive times. Ann Thorac Surg 2010; 89: 14481457.

15. Okita $\mathrm{Y}$, Minatoya K, Tagusari O, Ando M, Nagatsuka K, Kitamura S. Prospective comparative study of brain protection in total aortic arch replacement: Deep hypothermic circulatory arrest with retrograde cerebral perfusion or selective antegrade cerebral perfusion. Ann Thorac Surg 2001; 72: 72-79.

16. Okita Y, Okada K, Omura A, Kano H, Minami H, Inoue T, et al. Total arch replacement using selective antegrade cerebral perfusion as the neuroprotection strategy. Ann Cardiothorac Surg 2013; 2: $169-174$.

17. Ganapathi AM, Hanna JM, Schechter MA, Englum BR, Castleberry $\mathrm{AW}, \mathrm{Gaca} \mathrm{JG}$, et al. Antegrade versus retrograde cerebral perfusion for hemiarch replacement with deep hypothermic circulatory arrest: Does it matter? A propensity-matched analysis. J Thorac Cardiovasc Surg 2014 April 13, doi:10.1016/j.jtcvs.2014.04.014.

18. Wiedemann D, Kocher A, Dorfmeister M, Vadehra A, Mahr S, Laufer G, et al. Effect of cerebral protection strategy on outcome of patients with Stanford type A aortic dissection. J Thorac Cardiovasc Surg 2013; 146: 647-655.

19. Comas GM, Leshnower BG, Halkos ME, Thourani VH, Puskas JD, Guyton RA, et al. Acute type A dissection: Impact of antegrade cerebral perfusion under moderate hypothermia. Ann Thorac Surg 2013; 96: $2135-2141$.

20. Etz CD, von Aspern K, da Rocha E, Silva J, Girrbach FF, Leontyev $\mathrm{S}$, et al. Impact of perfusion strategy on outcome after repair for acute type A aortic dissection. Ann Thorac Surg 2014; 97: 78-85.

21. Usui A, Yasuura K, Watanabe T, Maseki T. Comparative clinical study between retrograde cerebral perfusion and selective cerebral perfusion in surgery for acute type A aortic dissection. Eur J Cardiothorac Surg 1999; 15: 571-578.

22. Ehrlich MP, Fang WC, Grabenwöger M, Kocher A, Ankersmit J, Laufer G, et al. Impact of retrograde cerebral perfusion on aortic arch aneurysm repair. J Thorac Cardiovasc Surg 1999; 118: 1026-1032.

23. Carvalho EM, Gabriel EA, Salerno TA. Pulmonary protection during cardiac surgery: Systematic literature review. Asian Cardiovasc Thorac Ann 2008; 16: 503-507.

24. Kilpatrick B, Slinger P. Lung protective strategies in anaesthesia. $\mathrm{Br}$ J Anaesth 2010; 105(Suppl 1): i108-i116.

25. Atluri P, Macarthur JW. Novel strategy to improve end-organ function with pulsatile cardiopulmonary bypass. Circ J 2012; 76: 10871088.

26. Carvalho EM, Gabriel EA, Salerno TA. Pulmonary protection during cardiac surgery: Systematic literature review. Asian Cardiovasc Thorac Ann 2008; 16: 503-507.

27. Rodriguez-Blanco YF, Garcia L, Brice T, Ricci M, Salerno TA. Deep hypothermic circulatory arrest with lung perfusion/ventilation in a patient with acute type A aortic dissection. Case Rep Med 2012; 2012: 631494 .

28. Pacini D, Leone A, Di Marco L, Marsilli D, Sobaih F, Turci S, et al. Antegrade selective cerebral perfusion in thoracic aorta surgery: Safety of moderate hypothermia. Eur J Cardiothorac Surg 2007; 31: $618-622$.

29. Luehr M, Bachet J, Mohr FW, Etz CD. Modern temperature management in aortic arch surgery: The dilemma of moderate hypothermia. Eur J Cardiothorac Surg 2014; 45: 27-39.

30. Klodell CT, Hess PJ, Beaver TM, Clark D, Martin TD. Distal aortic perfusion during aortic arch reconstruction: Another tool for the aortic surgeon. Ann Thorac Surg 2004; 78: 2196-2198.

31. Luo HY, Hu KJ, Zhou JY, Wang CS. Analysis of the risk factors of postoperative respiratory dysfunction of type A aortic dissection and lung protection. Perfusion 2009; 24: 199-202. 